The paper was accepted for publication in journal "Polymer Testing" on 26.11.2019 and published online on 29.11.2019.

DOI: https://doi.org/10.1016/j.polymertesting.2019.106262

\title{
The effect of short fiber orientation on long term shear behavior of $40 \%$ glass fiber reinforced polyphenylene sulfide
}

\author{
Alen Oseli ${ }^{1}$, Ted Prodan ${ }^{1}$, Egon Susić ${ }^{2}$, Lidija Slemenik Perše ${ }^{1, *}$ \\ ${ }^{1}$ University of Ljubljana, Faculty for Mechanical Engineering, Laboratory of \\ Experimental Mechanics, Ljubljana, Aškerčeva ulica 6, 1000 Ljubljana, Slovenia \\ ${ }^{2}$ Danfoss Trata, d.o.o., Ulica Jožeta Jame 16, 1000 Ljubljana, Slovenia
}

\begin{abstract}
:
Mechanical performance of SFRP depends on various factors (fiber fraction, geometry, etc.), among which the fiber orientation is difficult to predetermine, yet it needs to be considered during product design and manufacturing. This is important for parts with complex geometry and varying wall thicknesses, since variations in fiber orientation within the part, if not properly analyzed, may lead to unexpected or premature part failure. In our research, we investigate the effect of fiber orientation on the long-term time-dependent behavior in shear for polyphenylene sulfide with 40 wt.\% glass fiber reinforcement. Our results show that fiber orientation influences the magnitude of creep compliance (load transfer from matrix to fiber), however, the time-dependency and time-temperature relationship remains the same, regardless of the fiber orientation, suggesting that the composite time-dependency and thermal properties is solely governed by the matrix material.
\end{abstract}

Keywords: short fiber reinforced composites; fiber orientation; time-dependent mechanical properties; creep process; time-temperature superposition

\footnotetext{
* Corresponding author:

Phone.: + 386016207 100; E-mail: lidija.slemenik.perse@fs.uni-lj.si
} 


\section{Introduction}

Among various composite materials (metal, ceramic, carbon-carbon, etc.), polymer composites offer the widest application rage (automotive, aerospace, naval, etc.) mainly due to their cost-effective production, and relative high strength [1]. Historically, long-fiber (continuous fibers) thermoset polymer composites dominated due to their high thermomechanical performance; however, they pose limitations on the product manufacturing flexibility and are challenging to recycle. On the other hand, short-fiber (discontinuous fibers) thermoplastic polymer composites offer inferior mechanical properties, but they can be processed with versatile and automated processes, such as injection-molding, and are easier to recycle. As a result, short fiber reinforced polymers (SFRP) are rapidly gaining importance in product manufacturing, and gradually rolling out conventional materials, including long-fiber polymer composites, in a number of applications.

Mechanical performance of SFRP not only depends on the properties of the polymer matrix and fibers, but also on other parameters, such as the fiber fraction (concentration), fiber functionalization (grafting, plasma treatment, etc.), fiber geometry (diameter vs. length, etc.) and distribution of fibers inside polymer matrix. Past researches show that an increase in fiber fraction improves the composite strength (i.e., increases the Young's modulus, maximal stress, etc.) by sacrificing ductility (i.e., reduction in maximal strain and strain at rupture, etc.) [2-4]. Moreover, viscoelastic measurements have already shown that by increasing the fiber fraction, the composite becomes stiffer (i.e., increase in storage modulus $E^{\prime}$ ), whereas the material damping properties decrease (i.e., decrease in loss modulus $E^{\prime \prime}$ and damping factor $\tan \delta$ ) [56]. Literature also shows the effect of fiber fraction on time-dependent mechanical properties. By increasing the fiber fraction, the material response magnitude increases (i.e., increase in relaxation modulus or decrease in creep compliance), and material time-dependency decreases (decrease in relaxation or creep rate), since the fibers may be obstructing the polymer's molecular mobility [7-11]. It's important to mention i.) the existence of a minimum (critical) fiber fraction, which should be exceeded in order to strengthen the composite with the addition of fibers, and ii.) the existence of a maximum (optimal) fiber fraction, at which the composite reaches the highest strength. These two quantities are also related to geometrical parameters, such as fiber arrangement, spacing between the fibers and their orientation [12]. Another parameter that influences the mechanical properties of SFRP is the fiber functionalization or sizing. By functionalizing the surface of the fibers (with chemical agents, plasma treatment, 
etc.) one can significantly improve the adhesion between the matrix and the fiber, and consequently, the load transmission efficiency between the two, which results in enhanced mechanical properties of SFRP [13-16]. The fiber diameter, length (i.e., aspect ratio) and distribution of fibers also affect the mechanical properties of SFRP. It was shown that there is an optimal (critical) fiber length, up to which the composite mechanical properties increase, and above which the mechanical properties start gradually decreasing [5, 17-18]. This drop is related to the so called "reunion phenomenon", where clusters of entangled fibers cause voids, which reduce the adhesion between the matrix and the fiber [18]. Literature shows that there is also an optimal (critical) fiber diameter, up to which the composite mechanical properties increase, and above which the composite properties start gradually decreasing [21] (probably related to the increase in the voids between fibers and matrix). However, different researchers detected no changes in mechanical properties when varying fiber diameter [14, 19-20].

While almost all above mentioned influencing parameters are usually preselected based on the desired SFRP structural performance in parts, the fiber orientation and distribution are parameters that are difficult to predetermine. The fiber orientation mainly depends on the melt flow characteristics during manufacturing, which depend on rheological properties of the melt (viscosity, viscoelastic properties, etc.), processing parameters (injection temperature, pressure, etc.), product complex geometry (tool complexity) [22]. All these are nowadays under extensive research utilizing advanced numerical simulations. Nonetheless, two major fiber orientation layers can be observed within the cross-section of SFRP product wall. The first major layer is called the "shell", which has randomly distributed fibers and the second major layer is called the "core" and consists of fibers oriented in the melt flow direction. Literature shows that the core layer may be composed of multiple sub layers, where some may have fibers oriented transverse to flow direction. This phenomenon is known as the "coring effect", and it depends on above mentioned manufacturing variables [22-23]. Literature also shows that fiber orientation significantly affects the mechanical properties of SFRP. If fibers are longitudinally oriented (parallel to the loading direction), mechanical properties are improved due to the efficient load transfer from matrix to fiber, whereas in case of transversely oriented fibers (perpendicular to the loading direction) only small or negligible increase in mechanical properties is observed compared to the non-reinforced (or neat) material [24-25]. Thus, it's important to consider the fiber orientation during product design and manufacturing. Furthermore, since polymers are time-dependent materials, the structural and functional lifetime of such products mainly depend on the fiber orientation, particularly when dealing with 
products with complex geometry and varying wall thicknesses. Several research works show that fibers, oriented in line with the external loading, profoundly improve the magnitude of material response (increase in relaxation modulus or decrease in creep compliance) and decrease time-dependency of the composite (decrease in the relaxation and creep rate) $[8,11$, 26-27], which follows the same notion as the effect of fiber fraction on the composite behavior. The reason for increased material response lies in more efficient load transmission from the matrix to fiber, while the reduction in time-dependency is the result of fibers obstructing the molecular mobility. However, literature shows time-dependent behavior of composites in a relatively narrow experimental window, ranging from $1000 \mathrm{~s}$ to $10000 \mathrm{~s}$, where long-term behavior is not visible. Despite this lack of data, we suggest that the time-dependency of a composite material shouldn't significantly change neither with varying fiber fraction nor fiber orientation, and that the composite time-dependent behavior is mainly governed by the timedependent behavior of the matrix (polymer and its inherent molecular structure). Polymer molecules and fibers display widely different size magnitudes, so it is unlikely that the fibers could effectively obstruct the polymer's movement. However, time-dependency of the composite may be influenced by certain type of fibers, i.e., carbon fibers, which restrict molecular mobility close to fiber surface [8].

In our research we investigated the effect of fiber orientation on time-dependent behavior of SFRP, with emphasis on the effect of fiber orientation on the magnitude of the material response, time-dependency, and thermal shift function. Investigation was performed on polyphenylene sulfide with 40 wt.\% glass fiber reinforcement (PPS-GF40), a commercially available and widely used composite material in automotive and other industries. Utilizing the time-temperature superposition principle, the long-term behavior of the material was determined in shear reaching $\sim 30$ years $\left(10^{9} \mathrm{~s}\right)$, which could be used for effectively predicting the time-dependent behavior of products composed of PPS-GF40 that require long-term structural and functional performance. Additionally, the paper presents a detailed experimental procedure for a reliable long-term characterization of such materials.

\section{Experimental}

\subsection{Sample Preparation}

As shown in Fig. 1a, square plates of polyphenylene sulfide with 40 wt.\% glass fiber reinforcement, i.e. PPS-GF40, (Fortron MT 9140L4, Ticona) were injection molded according 
to the manufacturer specifications [28]. The injection molding machine (Arburg 150S, Germany) was equipped with a thin film gate tool to orient the glass fibers in the melt flow direction. Three specimens were cut out from each molded square plate (Fig. 1b), so that the fibers orientation in the specimens corresponded to $0^{\circ}$ (along the melt flow direction), $45^{\circ}$, and $90^{\circ}$ (perpendicular to the melt flow direction).
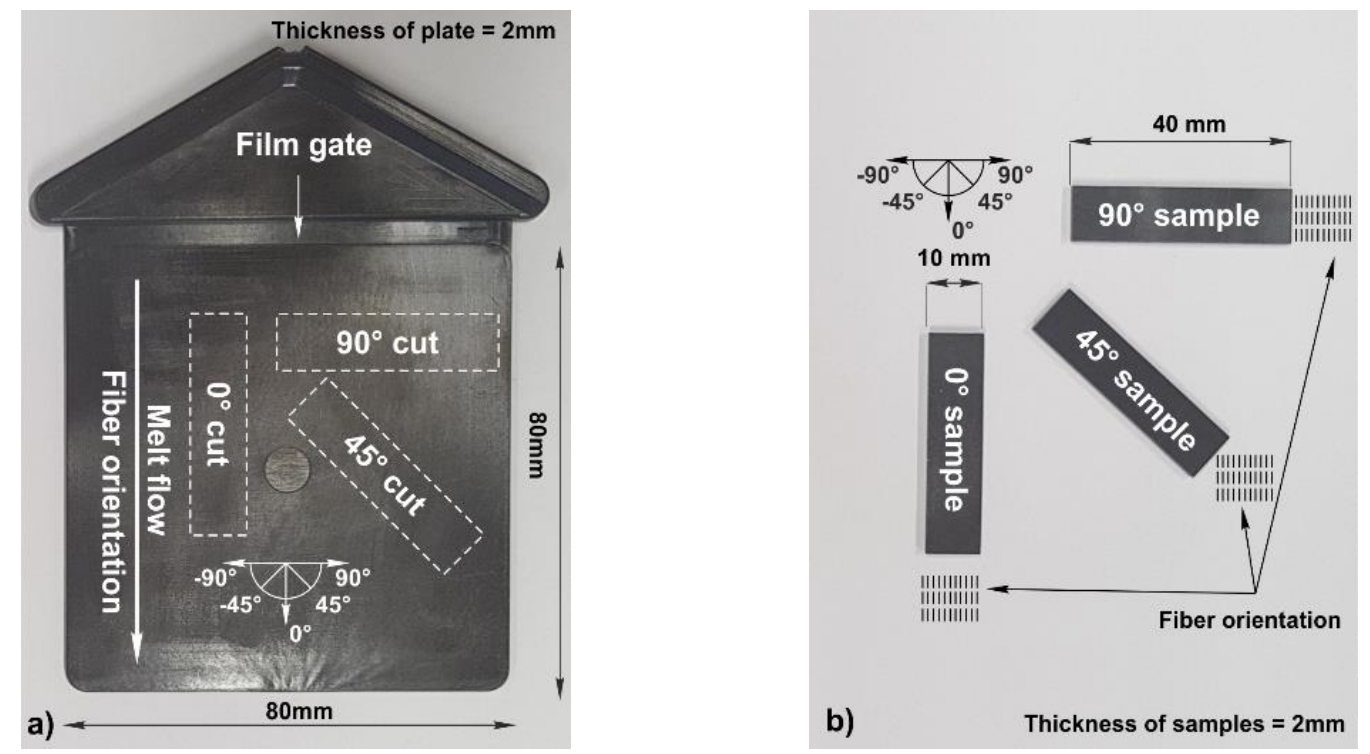

Fig. 1. a) Injection molded square plate with a film gate and b) samples with $0^{\circ}, 45^{\circ}$, and $90^{\circ}$ fiber orientation.

\subsection{Coring effect and fiber orientation analysis}

To evaluate i.) the coring effect (alignment of fibers transverse to flow direction, i.e., along the 22-axis), and ii.) the fiber orientation, samples were examined by an optical microscope (Karl Zeiss, Axioskop 2 MAT, Germany) at 50x magnification. Fig. 2a shows the $0^{\circ}$ sample, cut, sanded and polished parallel to the 11-33 plane (for plane orientation see Fig. 2b). From the figure one can observe two external "shell" layers (dark grey, $\sim 200 \mu \mathrm{m}$ in thickness with randomly orientated fibers) and one inner "core" layer (light grey, 1600 $\mu \mathrm{m}$ thickness with oriented fibers in the flow direction). Based on results no coring effect was present in prepared samples. 


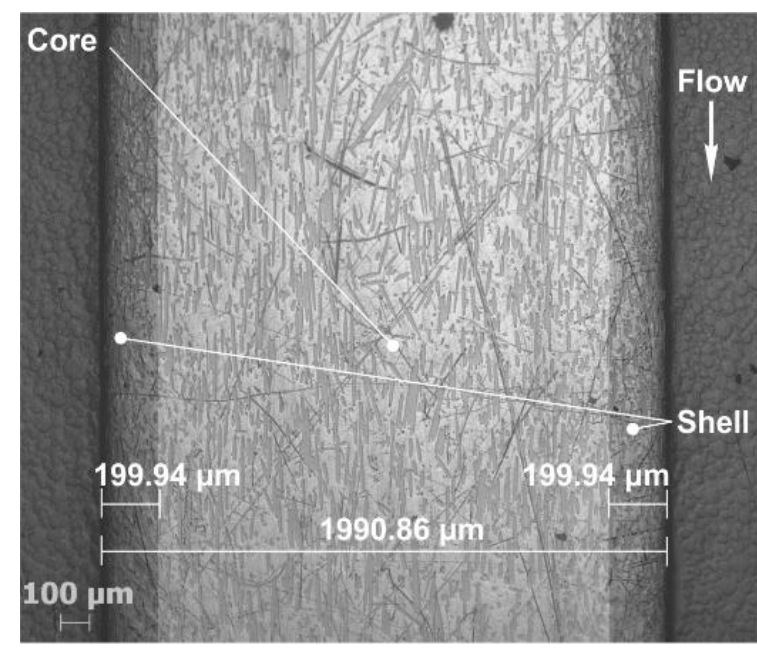

a)

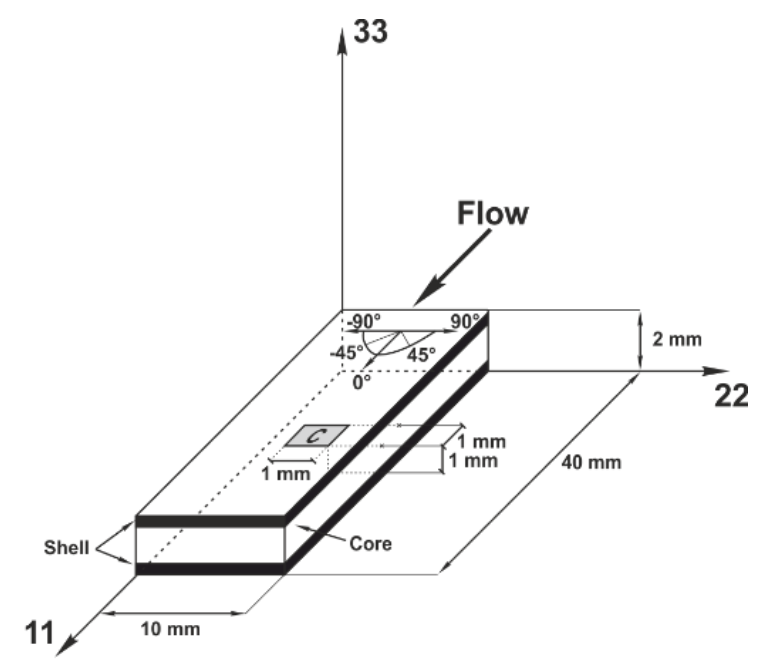

b)

Fig. 2. a) Dimensions of shell and core in the $0^{\circ}$-sample and b) schematic diagram of sample, indicating main directions, orientation, control area $C$ and corresponding dimensions.

To analyze the fiber orietntation distribution, samples for were cut, sanded and polished parallel to the 11-22 plane (for plane orientation see Fig. 2b). Analysis was than performed on a $1 \mathrm{~mm}^{2}$ control area, designated as $C$ using ImageJ, a freely available software for image analysis. Fig. 3 shows fiber distribution for the three orientations of the fibers. The results showed that for the $0^{\circ}$ sample the dominant orientation was $-5^{\circ}$ (exactly $-5,6^{\circ}$ ), for the $45^{\circ}$ sample it was $-45^{\circ}\left(\right.$ exactly $\left.-47,3^{\circ}\right)$, and for the $90^{\circ}$ sample it was $-90^{\circ}$ (exactly $-88^{\circ}$ ). The fiber distribution diagrams for the three fiber orientations exhibited similar heights and widths, indicating that the fibers were homogeneously (uniformly) dispersed in the control area $C$. Additionaly average fiber dimensions were determined, i.e., diameter, length, and aspect ratio (none provided by the material manufacturer) as $\sim 10 \mu \mathrm{m}, \sim 300 \mu \mathrm{m}$, and $\sim 30$, respectively. 


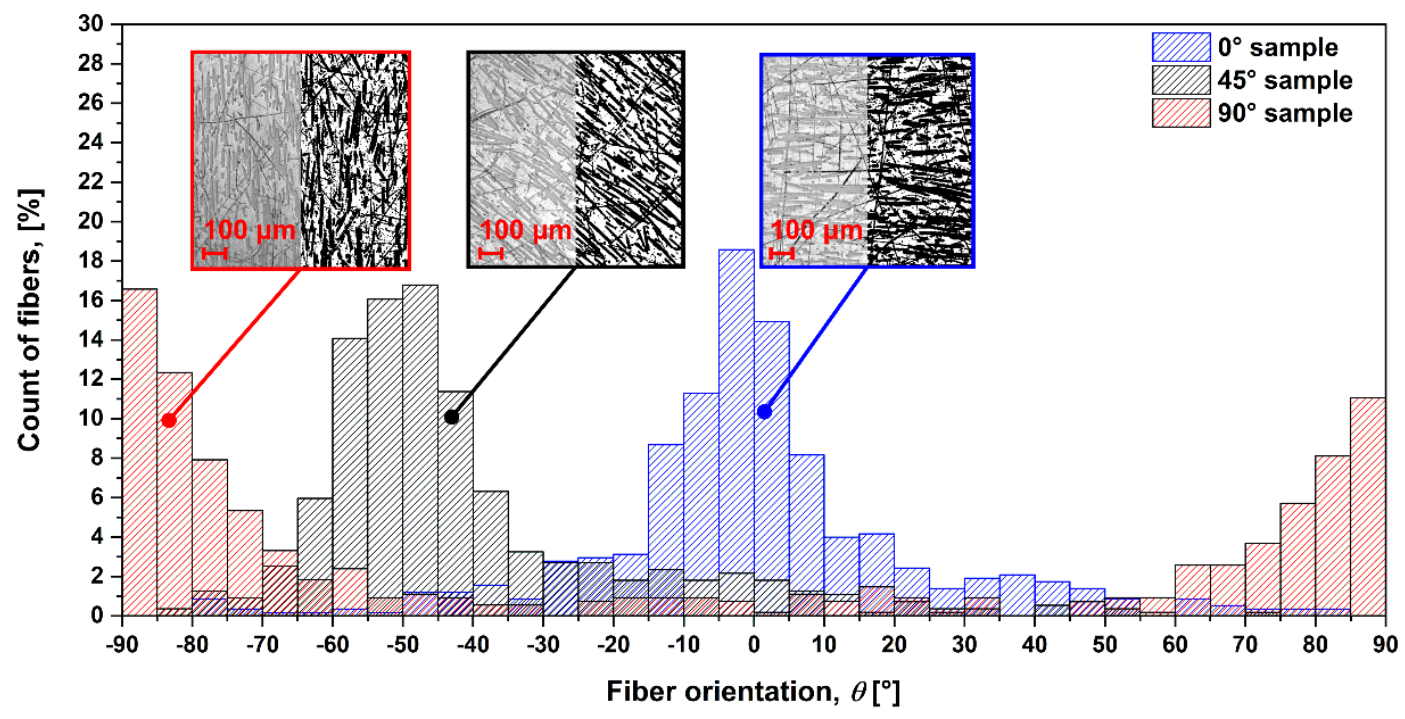

Fig. 3. Density of fiber distribution as a function of fiber orientation.

\section{$\underline{2.2 \text { Annealing procedure }}$}

Annealing removes (or at least minimizes) the residual thermo-mechanical stresses, which remain in the samples due to the process conditions during their preparation (i.e., injection molding, cutting, etc.). When the thermodynamic equilibrium state inside material is not reached, the material exhibits physical ageing, a process where time-dependent changes in physical properties occur without material being exposed to any external load. Physical ageing may lead to significant errors, in our case in long term time-dependent behavior [29-31]. The procedure of annealing process is divided in three steps: i.) determination of glass transition temperature (to determine the annealing temperature); ii.) conditioning of the samples (thermal treatment of samples); and iii.) determination of physical ageing (verification if thermodynamic equilibrium inside the sample was reached).

\subsubsection{Determination of glass transition temperature}

In the present work, the glass transition temperature $T_{\mathrm{g}-\mathrm{DMA}}$ for all three fiber orientations was determined using dynamic mechanical tests (DMA) in bending mode (single cantilever) on a DMA analyzer (TA Instruments, Q800, USA). The loading amplitude was set to $A=30 \mu \mathrm{m}$ (which was within the material linear viscoelastic region), the loading frequency was $f=1 \mathrm{~Hz}$, and the heating rate was set to $\mathrm{d} T / \mathrm{d} t=3{ }^{\circ} \mathrm{C} / \mathrm{min}$, as specified in ISO 6721-11:2012 [32]. Measurements were conducted in the temperature range from $25^{\circ} \mathrm{C}$ to $115^{\circ} \mathrm{C}$. Fig. 4 shows the temperature loading profile, and the DMA results (i.e., storage modulus $E^{\prime}$, loss modulus $E^{\prime \prime}$, and loss factor $\tan \delta$ ) as a function of temperature for all three fiber orientations. 

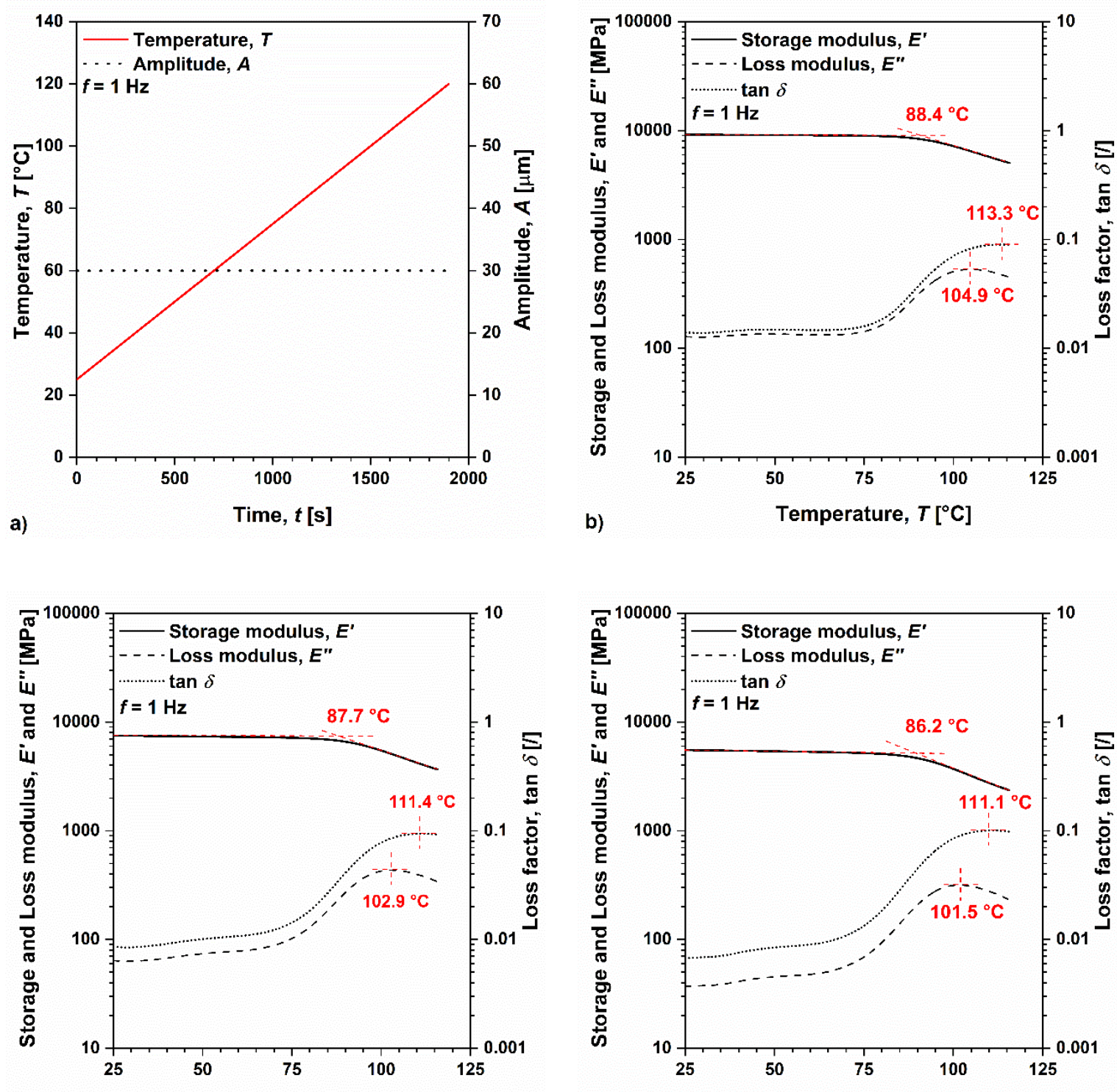

c)

Temperature, $T\left[{ }^{\circ} \mathrm{C}\right]$

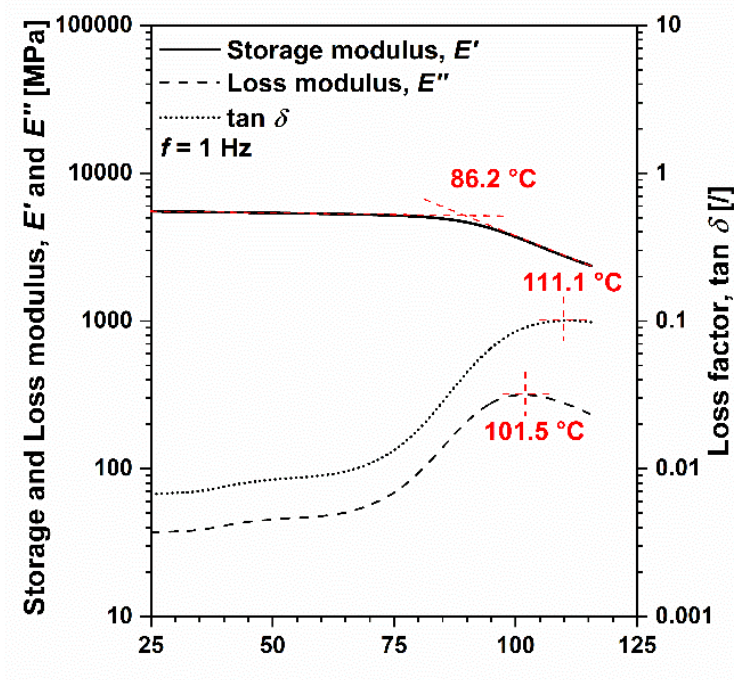

d)

Temperature, $T\left[{ }^{\circ} \mathrm{C}\right]$

Fig. 4: a) Temperature-loading profile and DMA results (storage modulus $E$ ', loss modulus $E^{\prime \prime}, \tan \delta$, glass transition temperatures) for samples with b) $0^{\circ}$, c) $45^{\circ}$, and d) $90^{\circ}$ fiber orientation.

The DMA technique defines the glass transition temperature $T_{\mathrm{g}}$ as the temperature where the loss modulus $E$ "' reaches the peak value, i.e. the material undergoes the maximum change in molecular mobility) [32-33]. For PPS-GF40 the DMA tests determined the glass transition temperature $T_{\mathrm{g}-\mathrm{DMA}} \approx 100{ }^{\circ} \mathrm{C}$, which was $10{ }^{\circ} \mathrm{C}$ higher than specified by the manufacturer's datasheet, which states that $T_{\mathrm{g}-\mathrm{DSC}} \approx 90^{\circ} \mathrm{C}$ [28]. This difference is the result of a different glass transition temperature measuring technique, i.e., Differential Scanning Calorimetry (DSC). It is known that the DSC technique can be used only on neat (non-fiber reinforced) materials, since the sensitivity is too small to observe the $T_{\mathrm{g}}$ on highly filled material such as PPS-GF40. 
Besides $T_{\mathrm{g} \text {-DMA }}$, DMA tests also determined the storage modulus $E$ ' onset temperature $\approx 87^{\circ} \mathrm{C}$, at which the mechanical properties begin to decrease and the $\tan \delta$ peak temperature $\approx 112{ }^{\circ} \mathrm{C}$, describing the peak damping characteristics of the material. From the DMA results one can also observe the decrease in mechanical properties (i.e., storage modulus $E^{\prime}$, loss modulus $E$ ', and loss factor $\tan \delta$ ) with changing of fiber orientation from the $0^{\circ}$ sample (fibers oriented in the direction of the applied load) to $90^{\circ}$ (fibers oriented perpendicular to the applied load).

\subsubsection{Temperature conditioning of the samples}

In order to reach thermodynamic equilibrium, samples were conditioned in a laboratory temperature chamber (Kambič, SP105C, Slovenia), while enclosed in a small glass chamber with a nitrogen atmosphere to prevent oxidization of the samples. Prior to heating, the glass chamber with samples was flushed with nitrogen for $15 \mathrm{~min}$ with a flow rate of $1 \mathrm{l} / \mathrm{min}$. The samples were then heated to $T_{\text {annealing }}=140^{\circ} \mathrm{C}\left(T_{\mathrm{g}-\mathrm{DMA}}+40^{\circ} \mathrm{C}\right)$ and conditioned at this temperature for $t_{\text {annealing. }}=10$ hours. Next step was cooling of the samples to $T_{\text {room }}=25{ }^{\circ} \mathrm{C}$ at slow cooling rate of $\mathrm{d} T / \mathrm{d} t=0.1^{\circ} \mathrm{C} / \mathrm{min}$. For each fiber orientation, all dimensions (volume) of the samples were measured before and after temperature conditioning. Fig. 5a shows the temperature profile during sample conditioning, while Fig. 5b shows the change in sample volume before and after conditioning. Measurements indicate that sample volume decreased for $\sim 5 \mathrm{~mm}^{3}(0.5 \%)$ in average.
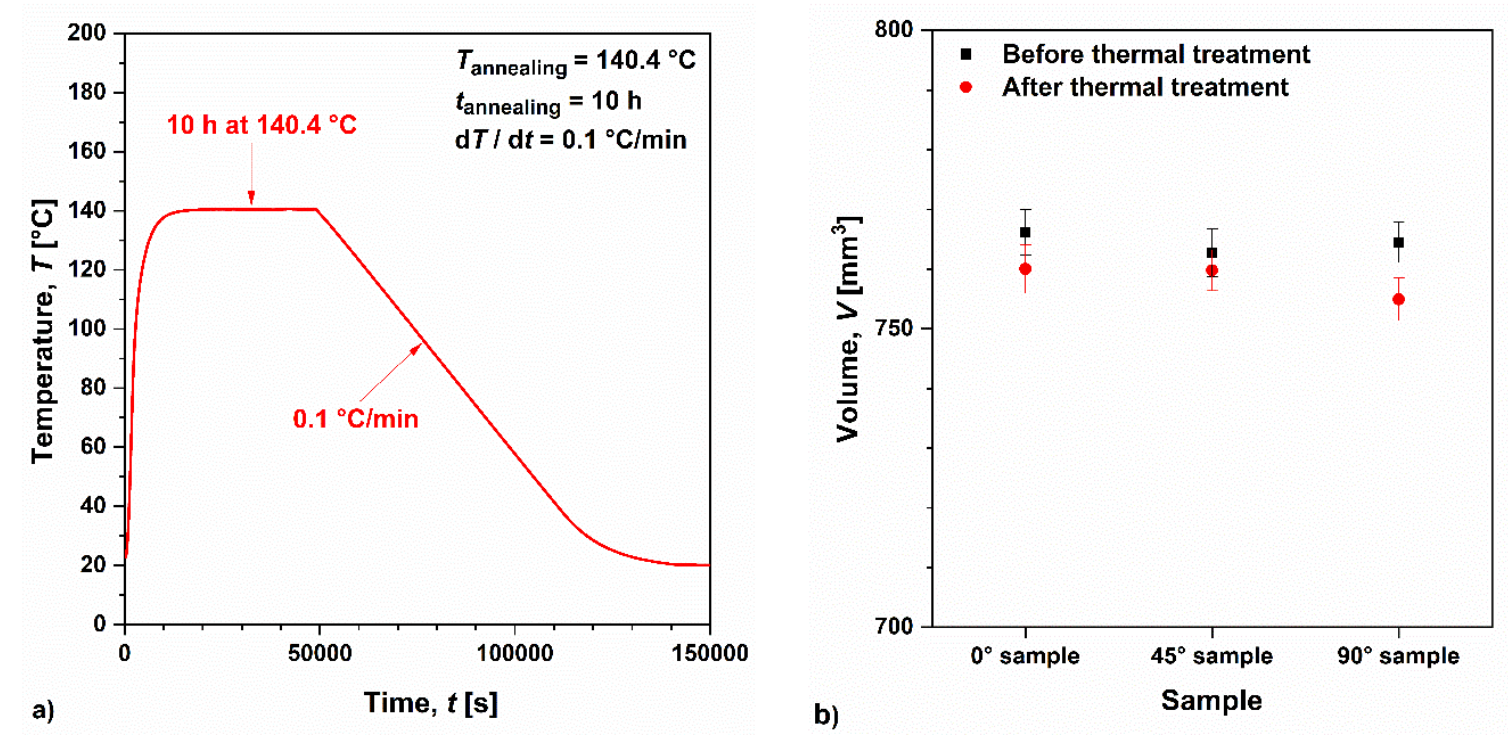

Fig. 5. a) Temperature profile during thermal treatment and b) change in volume before and after thermal treatment of samples with $0^{\circ}, 45^{\circ}$, and $90^{\circ}$ fiber orientation. 
As observed from Fig. 5b, the decrease in volume (shrinkage) is direct consequence of physical ageing. Prior to conditioning, samples were subjected to rapid cooling during sample preparation, i.e. injection molding, which "freezes" molecular mobility (ability of molecules to achieve different spatial configuration). Even though the mobility of molecules below $T_{\mathrm{g}}$ is hindered, side-chain movement initiate slow approach to equilibrium state [34], which can result in time-dependent change of physical properties (volume, mechanical properties, etc.) leading to possible profound error during analysis. However, by reheating material above $T_{\mathrm{g}}$ (inducing global molecular movement) followed by "slow" cooling, the molecules have time to rearrange and are able to achieve spatial configuration in which their energy and space potential is small, denoted as equilibrium state. Although we observed a decrease in volume, which indicates that the material is (or is approaching) the equilibrium state, it should be verified with creep measurements below $T_{g}$, whether this state was actually achieved.

Moreover, from the Fig. $5 \mathrm{~b}$ minor differences in volume change between samples with different fiber orientation can be observed after temperature conditioning. These differences can be attributed to thermo-mechanical stresses to which the samples were exposed prior to conditioning (thermal history of the samples) during injection molding process. Such stresses cannot be avoided and mainly depend on the mold geometry, temperature and temperature field in the mold, cutting the samples during the preparation, etc. As a result, various volume changes are observed after the release of these stresses, i.e. after temperature conditioning.

\subsubsection{Determination of physical ageing}

After temperature conditioning of the samples, "Physical ageing tests" were performed in order to determine if thermodynamic equilibrium was achieved. These measurements indicate changes in time-dependent mechanical properties when the material is for a certain period of time exposed to the temperature below $T_{\mathrm{g}}$. If time-dependent mechanical properties improve (due to a decrease in volume and free volume, which governs the creep process [35]), physical ageing is still present, which means that temperature conditioning of the samples was not proper. It is important to note that physical ageing cannot be completely avoided, but it can be minimized to a degree where its effects are negligible from the engineering point of view. This minimization can be achieved by appropriate selection of the annealing temperature, annealing time, and cooling rate [36].

Physical ageing tests were performed on a modular advanced rheological system (Thermo Scientific Haake MARS-II, USA) coupled with solid clamps. Test was performed in three sequential steps at the temperature $T_{\text {ageing }}=60^{\circ} \mathrm{C}\left(T_{\mathrm{g}-\mathrm{DMA}}-40^{\circ} \mathrm{C}\right)$. Each step consisted of one 
ageing period, and one loading period where shear creep compliance $J(t)$ was measured. The magnitude of the applied shear stress was $\tau_{\text {load }}=0.1 \mathrm{MPa}$ (within the linear viscoelastic range). In the first two sequential steps the samples were aged for $t_{\text {ageing }}=10000 \mathrm{~s}(\sim 3 \mathrm{~h})$ prior to

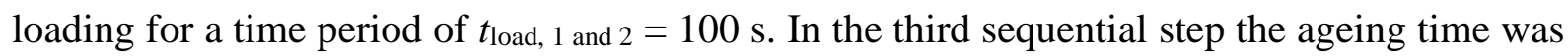
the same while the loading time was increased to $t_{\text {load-3 }}=1000 \mathrm{~s}$ (corresponding to experimental window of final creep measurements).

Fig. 6 shows the temperature-loading profile and the measurements of shear creep compliance $J(t)$ for all three fiber orientations during the physical ageing test, where the thick line represents the measurement of shear creep compliance $J(t)$, determined with Eq. (A.1), and the thin dashed lines represent the corresponding experimental error $\left(E_{\exp } \approx 1.8 \%\right)$, determined from the Eq. (A.4) (see Appendix A) [37]. Results of all three sequential step measurements were within the experimental error, which indicates that there was no change in the timedependent mechanical properties during the ageing periods, i.e. the physical ageing didn't occur in the observed time span, and the samples were in (or close to) thermodynamic equilibrium.
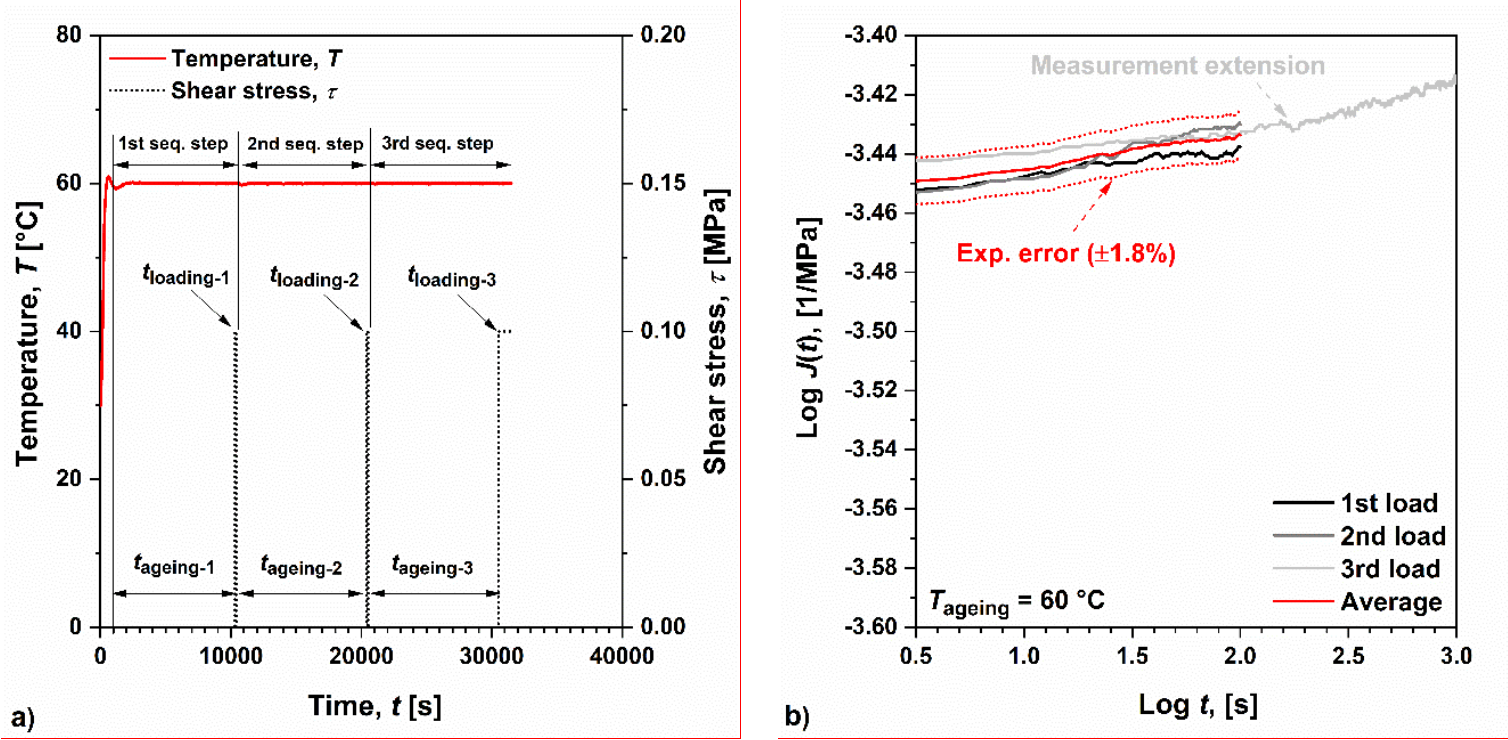

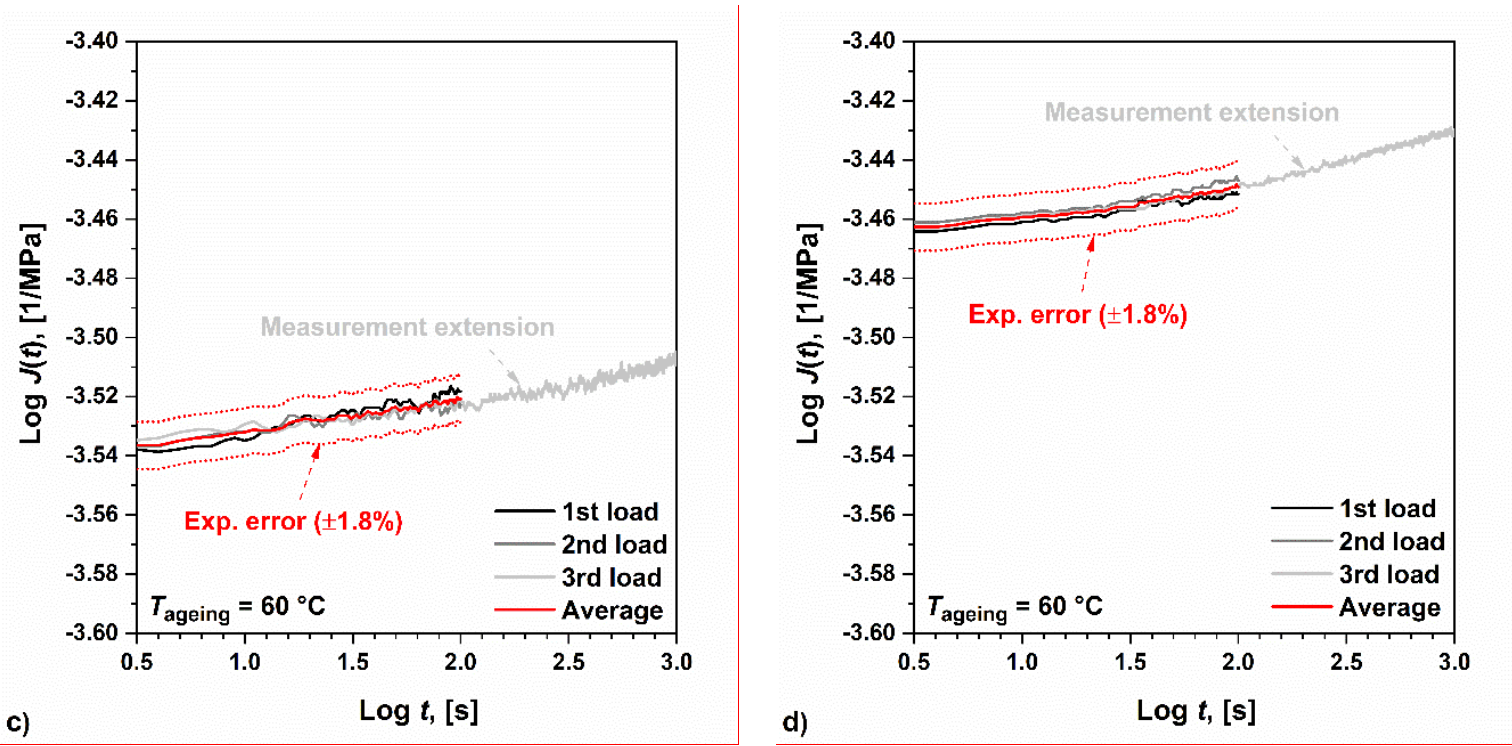

Fig. 6. a) Temperature-loading profile and creep results, i.e. shear creep compliance, $J(t)$ for samples with b) $0^{\circ}$, c) $45^{\circ}$, and d) $90^{\circ}$ fiber orientation.

From the presented results we can conclude, that thermal conditioning of the samples was proper, since no physical ageing was observed. This indicates that the thermal history (residual thermo-mechanical stresses from injection molding) of the samples was to a large extent erased. The annealing procedure has a profound importance in time-dependent mechanical characterization of viscoelastic materials and their composites, as well as during the analysis of their time-dependent mechanical properties using tools, such as the time-temperature superposition principle.

\subsection{Creep measurements}

Since the annealing procedure was successful as thermodynamic equilibrium in the samples was reached, no additional annealing in the rheometer was needed. Shear creep compliance $J(t)$ measurements were performed on all three fiber orientation samples (i.e., $0^{\circ}, 45^{\circ}, 90^{\circ}$ ) in segmental form at 13 different temperatures: 60, 65, 70, 75, 80, 85, 90, 95, 100, 105, 110, 120, $140{ }^{\circ} \mathrm{C}$. After the set temperatures was stabilized at a certain stabilization time $t_{\text {stabilization }}=$ $10000 \mathrm{~s}$ (to obtain a homogeneous temperature filed in the sample), each sample was loaded with a shear stress of $\tau_{\text {load }}=0.1 \mathrm{MPa}$ (within the linear viscoelastic range) for a duration of $t_{\text {load }}=1000 \mathrm{~s}$. The heating rate during the measurements was $0.1{ }^{\circ} \mathrm{C} / \mathrm{s}$. The complete temperature-loading profile for shear creep compliance $J(t)$ measurements is shown in Fig. 7. 


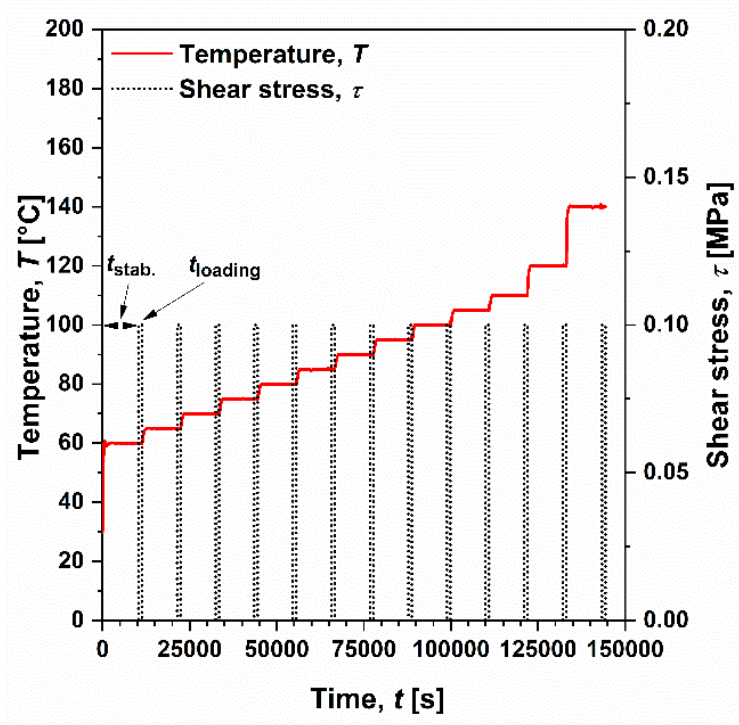

Fig. 7. Temperature-loading profile during shear creep compliance, $J(t)$, measurements.

\section{Results and discussion}

\section{$\underline{3.1 \text { Creep measurements }}$}

As a result of creep measurements, isothermal segments of shear creep compliance $J(t)$ were obtained determined with Eq. (A.1) (see appendix A). Maximal deviation from average value of segment was smaller than experimental error, i.e., $E_{\text {exp. }}= \pm 1.8 \%$, determined by Eq. (A.4), therefore, experimental error was used for further evaluation and analysis. Segments were used to generate master curve in order to determine the behavior of the material through longer period of time, by utilizing time-temperature superposition principle with the Closed Form ShiftingCFS algorithm (outline of algorithm is given Appendix B) [38-39]. Shifting of the segments was performed at reference temperature $T_{\text {ref. }}=90{ }^{\circ} \mathrm{C}$, which indicated the middle and the steepest isothermal segment of $J(t)$ in order to mitigate the shifting error. Additionally, analysis of the vertical shifting was also performed, however it can be neglected, since the vertical shift was within the experimental error, i.e., $E_{\exp }= \pm 1.8 \%$, as determined by Eq. (A.4) (see Appendix A).

Fig. 8 shows the combined results of creep measurements and shifting analysis for all three fiber orientations, i.e. $0^{\circ}, 45^{\circ}$ and $90^{\circ}$, respectively. From the Fig. 8 the following information could be obtained: i) isothermal segments of shear creep compliance $J(t)$, measured at the specified temperatures; ii) the master curve of shear creep compliance as determined at $T_{\text {ref. }}=90{ }^{\circ} \mathrm{C}$ (material function); and iii) the time-temperature relationship given by the shift 
factors, $\log a_{T}(T)$ (thermal shift function). The Figure also shows that within the observed temperature (from 60 to $140{ }^{\circ} \mathrm{C}$ ) or time ( 18 decades) range, shear creep compliance $J(t)$ changes from $J\left(t=10^{-9} \mathrm{~s}\right)=0.000316 \mathrm{MPa}^{-1}$ to $J\left(t=10^{9} \mathrm{~s}\right)=0.001259 \mathrm{MPa}^{-1}$. If we present this change as a shear relaxation modulus $G(t)$, this translates to a quite profound change from $G\left(t=10^{-9} \mathrm{~s}\right)=3164.56 \mathrm{MPa}$ to $G\left(t=10^{9} \mathrm{~s}\right)=794.28 \mathrm{MPa}$, which is $\sim 4 \mathrm{x}$ [40].

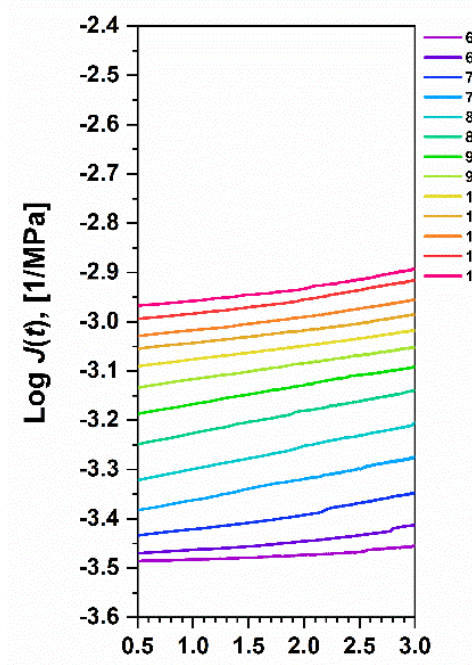

a)

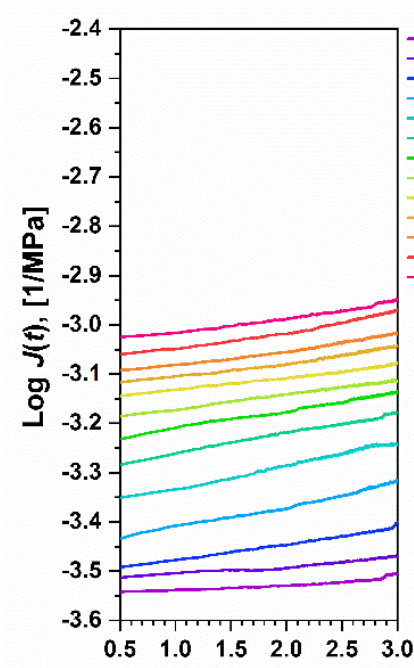

b)

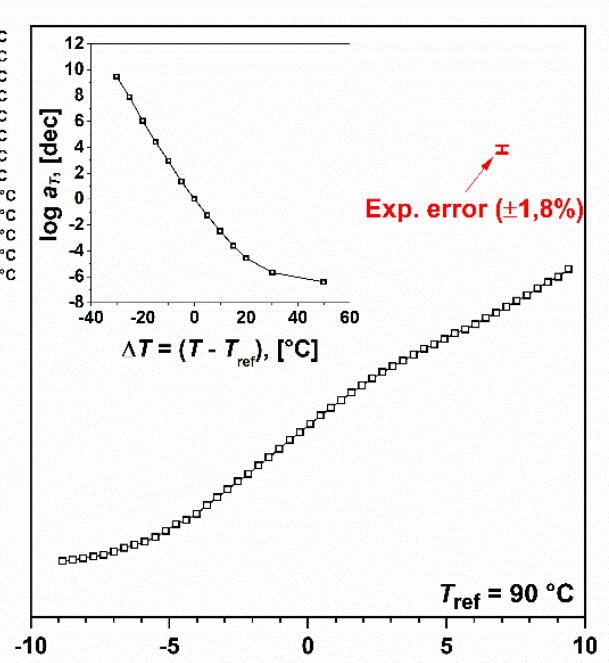

$\log t,[\mathrm{~s}]$

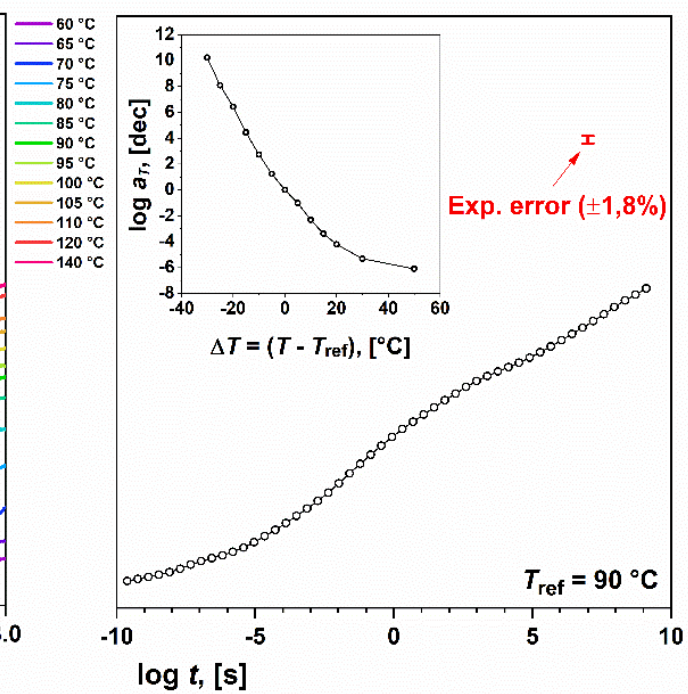




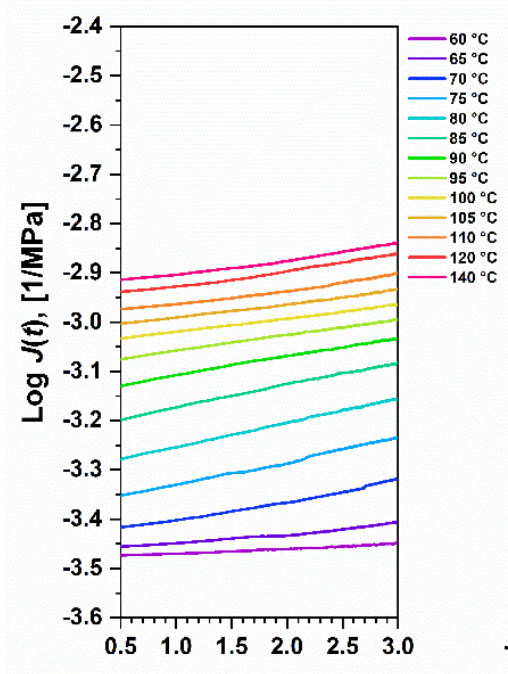

c)

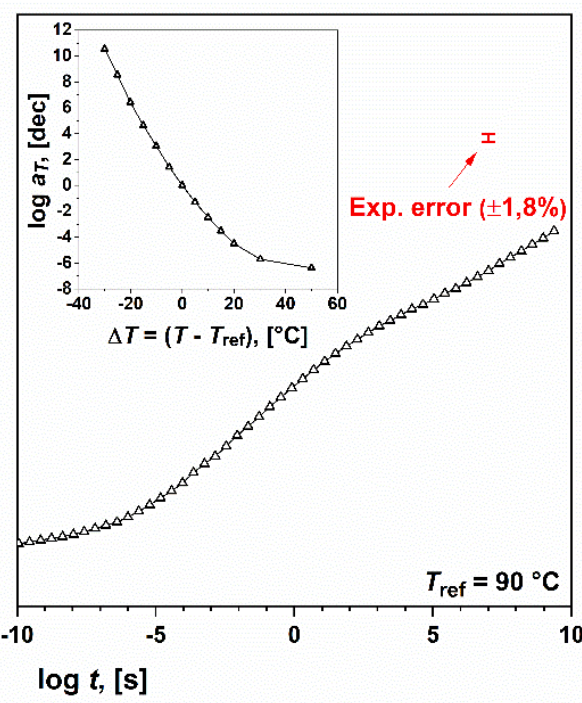

$\log t,[\mathrm{~s}$

Fig. 8. Isothermal segments, master curve, and the thermal shift function for the samples with a) $0^{\circ}$, b) $45^{\circ}$, and c) $90^{\circ}$ fiber orientation.

\subsection{Effect of fiber orientation on magnitude of material response}

By plotting the master curves of shear creep compliance $J(t)$ (also called material function) for the three fiber orientations (i.e., $0^{\circ}, 45^{\circ}$ and $90^{\circ}$ ), the change in magnitude of material response could be observed (Fig. 9a). This change is also apparent when observing the shear retardation spectrum $L(\lambda)$ (also called material transfer function) shown in Fig. 9b, calculated by the Windowing algorithm (a short description of the algorithm is given in Appendix C) [4142]. The results showed that the lowest values of deformation and consequently the material function $J(t)$, as well as the material transfer function $L(\lambda)$ were for the sample with $45^{\circ}$ fiber orientation. Such results are in line with the theory of continuum mechanics, since fibers are aligned in direction to resist maximal shear deformation, i.e. higher effective load transfer from matrix material to fibre. Moreover, one would expect equal responses between $0^{\circ}$ sample and $90^{\circ}$ sample. However, these differences in magnitude could be related to the principle fiber orientation to loading direction. Upon torsion (shear) loading, the fiber in $0^{\circ}$ sample are rotated and twisted ("bent out of plane") providing higher resistance to external load, while the fibers in $90^{\circ}$ sample are only rotated (and cannot be "bent out of plane"), thus they provide less resistance to torsion (shear) loading, therefore such orientation exhibits higher deformation and consequently higher material function and material transfer function than the rest. Here it is important to emphasise that the relative difference in magnitude between $90^{\circ}$ and $45^{\circ}$ sample was $\sim 15 \%$ and between $0^{\circ}$ and $45^{\circ}$ samples was $\sim 35 \%$, where values of $45^{\circ}$ sample were used as reference. 

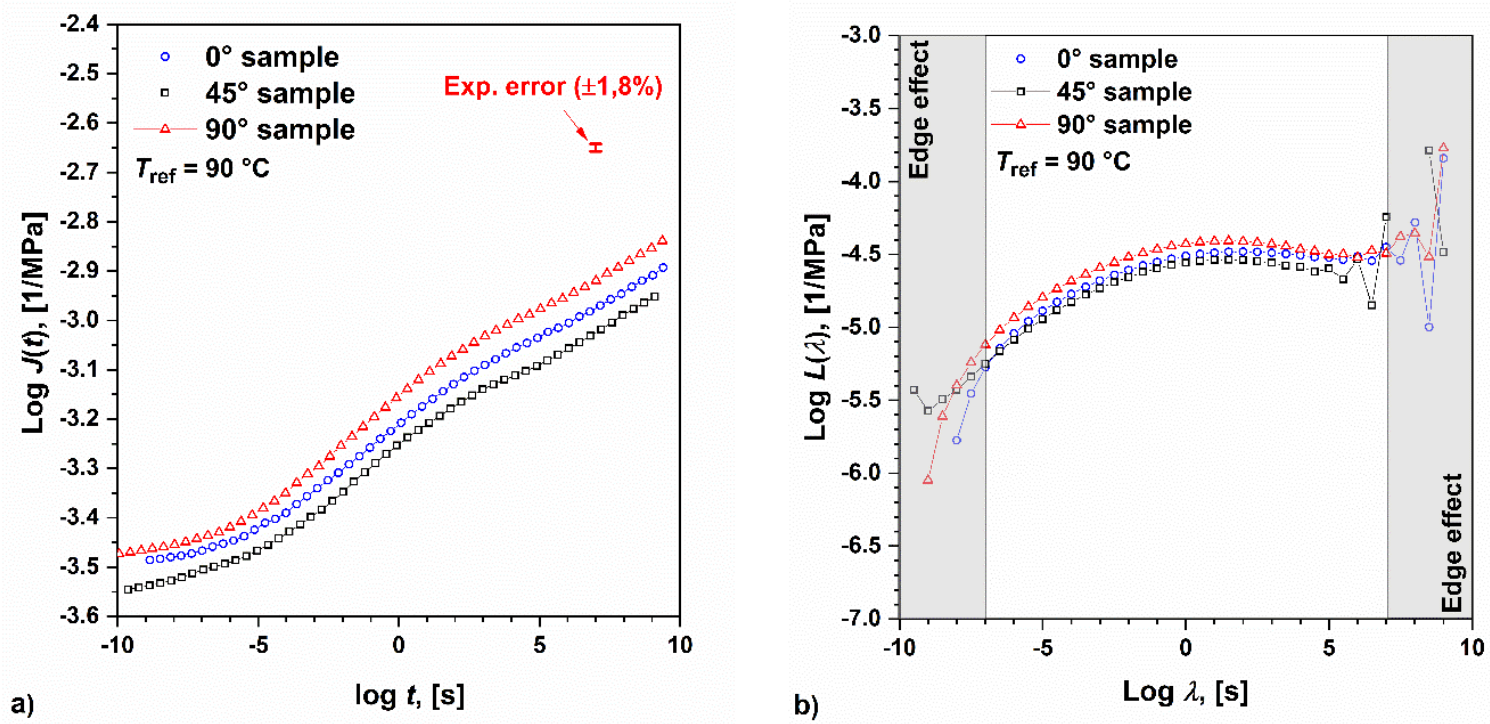

Fig. 9. a) Shear creep compliance master curves (material functions) and b) shear retardation spectra (material transfer function) for samples with $0^{\circ}, 45^{\circ}$, and $90^{\circ}$ fiber orientation.

\subsection{Effect of fiber orientation on time-dependency}

Next we observed effect of fiber orientation on material time-dependency. For this reason, material function (shear creep compliance) was normalized based on initial value of reference segment, i.e. $J\left(t=10 \mathrm{~s}, T=90^{\circ} \mathrm{C}\right)$, and material transfer function (shear retardation spectra) was normalized according to Eq. (C.3) see Appendix C, Fig. 10. Although such results do not have any applicative value, one can see that for material functions and transfer functions for samples with different fiber orientations drop on the same curve (within the experimental and numerical error). Here it has to be noted that some differences my be observed in material transfer function, due to edge effect caused by windowing procedure. Results suggest that the time-dependency of the material remains the same regardless of the fiber orientation. It seems that time-dependent behavior of composites under the investigation is solely governed by the behavior of the matrix material, i.e., the shape of material function and material transfer function stays the same within the observed time span. 

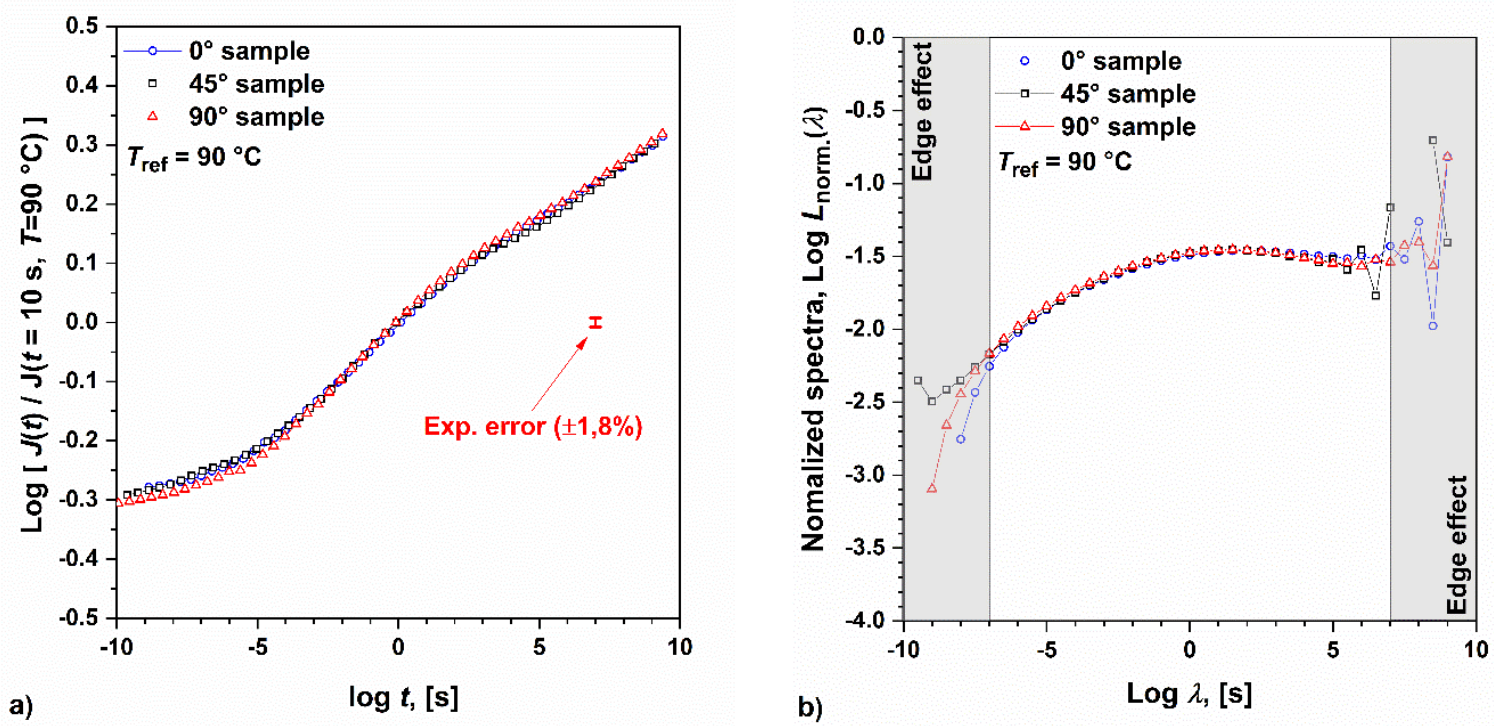

Fig 10. a) Normalized material functions and b) normalized material transfer functions for samples with $0^{\circ}, 45^{\circ}$, and $90^{\circ}$ fiber orientation.

\subsection{Effect of fiber orientation on thermal shift function}

The fact that fiber orientation does not affect the material time-dependency could also be observed through thermal-shift function by plotting shift factors for all three fiber orientations (i.e., $0^{\circ}, 45^{\circ}$ and $90^{\circ}$ ) on the same plot (Fig. 11). From the results it can be seen that shift factors for the samples with various fiber orientations follow the same curve. Beside time-dependency this also indicates that time-temperature relationship and therefore thermal properties of composite are not altered by fiber orientation. However, at lower temperatures, i.e., 60 and $65{ }^{\circ} \mathrm{C}$ (rectangle in Fig. 11), the shifting error can be observed, which could be the result of small residual stresses that were not completely removed with the annealing procedure and presents occurrence of minor physical ageing. Since the time-dependent behavior, and consequently the time-temperature relationship, for all three orientations is the same, the shift factors were averaged and the WLF equation (Eq. (D.1) in Appendix D) was used to model the thermal shift function, where $c_{1}$ and $c_{2}$ are the material constants (WLF constants are shown in Fig. 12) [35, 43]. 


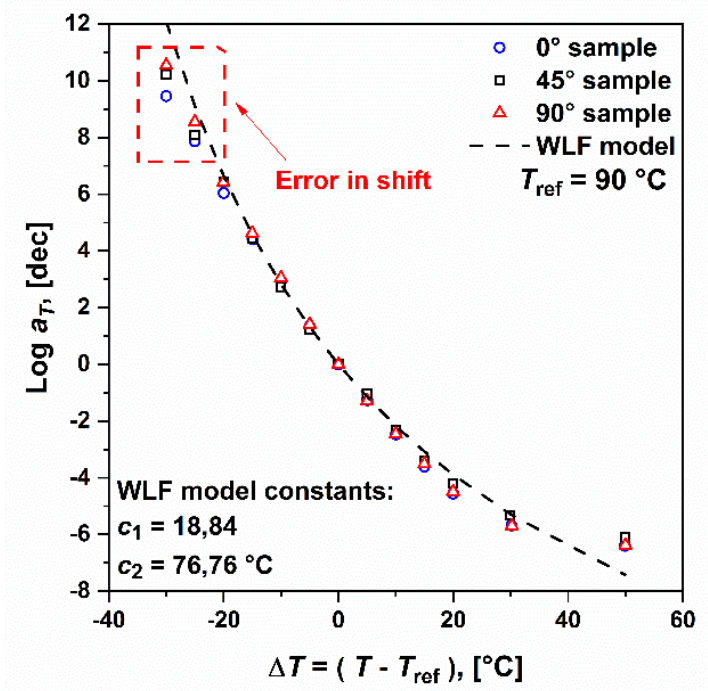

Fig. 11. Shift factors and thermal shift function (WLF model) for samples with $0^{\circ}, 45^{\circ}$, and $90^{\circ}$ fiber orientation.

\section{Summary and conclusions}

Short fiber reinforced polymers (SFRP) nowadays continue to replace traditional materials (such as, metals, wood, etc.) in various industrial applications (e.g., aerospace, automotive, naval, etc.) due to their efficient load carrying capacity, cost effectiveness, and recyclability. One of such materials is also polyphenylene sulfide with $40 \%$ glass fiber reinforcement (PPSGF40), which was studied in the present work. It is commonly used in automated processes (i.e. injection molding, extrusion) to produce various products with complex geometry. Due to geometrical complexity (thin walls, reinforcing ribs, etc.), these products tend to possess varying fiber orientations resulting in a decrease of the product load carrying capacity, which can lead to its premature failure (decrease of structural and functional lifetime of the product).

The scope of presented research was to evaluate the effect of fiber orientation on long term (time-dependent) behavior of PPS-GF40 in shear (torsion), by determination of the material function, i.e. shear creep compliance $J(t)$, material transfer function, i.e. shear retardation spectra $L(\lambda)$, and the thermal shift function, i.e. shift factors $\log a_{T}$. A detailed research was performed i) on the sample preparation to evaluate coring effect and fiber orientation distribution in the material, as well as ii) on the sample temperature conditioning to evaluate and minimize the effects of physical ageing. Based on the results no coring effect and physical ageing was observed on prepared samples. It's important to note that physical ageing can lead 
to significant errors in predicting the long-term material behavior, especially when using the time-temperature superposition principle.

The results, obtained in the present study on shear creep analysis can be divided in to three groups: (a) the effect of fiber orientation on the magnitude of the material response, (b) the effect of fiber orientation on the material time-dependency, and (c) the effect of fiber orientation on materials time-temperature relation. For (a) it was shown that the fiber orientation affects the magnitude of material response, visible from the material function (shear creep compliance $J(t)$ ), as well as from the material transfer function $L(\lambda)$ (shear retardation spectra). The lowest material response was determined for $45^{\circ}$ sample, due to higher effective load transfer from matrix material to fibre. Interestingly, $0^{\circ}$ and $90^{\circ}$ sample did not exhibit same magnitude response, due to effect of principle fiber to loading direction, where $0^{\circ}$ samples performs better (smaller values of deformation, material function and material transfer function) than $90^{\circ}$ sample. For (b) it was shown that, time-dependency of the material remains the same regardless of fiber orientation, since material function and material transfer function drop on the same curve (within experimental and numerical error) upon the normalization, which means that time-dependent behavior of composite is solely governed by matrix material. Furthermore, for (c) it was shown that the fiber orientation does not affect the time-temperature relationship and thus the thermal response of composite materials, since thermal shift functions for all three fiber orientations had the same temperature dependence.

\section{Acknowledgements}

The authors acknowledge the financial support from the Slovenian Research Agency (research core funding No. P2-0264) and the company Danfoss Trata d.o.o.

\section{Appendices}

Appendix A (Definition of shear creep compliance)

The shear creep compliance, $J(t)$, is determined as a ratio between time-dependent shear strain $\gamma(t)$ and constant shear stress, $\tau_{0}$ or with the torsional equation as [37]:

$$
J(t)=\frac{\gamma(t)}{\tau_{0}}=\frac{\varphi(t) K}{l M_{t}}
$$


where $l$ is length of the sample, $M_{\mathrm{t}}$ is torsional moment (load), $\varphi$ is angle (response), $t$ is time and $K$ is the torsional constant. Since we have used rectangular samples, a rectangular torsional constant $K$ is determined as:

$$
K=a b^{3}\left[\frac{16}{3}-3.36 \frac{a}{b}\left(1-\frac{b^{4}}{12 a^{4}}\right)\right], \text { for } a=\frac{w}{2} \geq b=\frac{h}{2}
$$

where $w$ is the width of the sample, $h$ the thickness of the sample, and $a$ and $b$ are halves of mentioned sample dimensions, respectively. The maximal shear stress, $\tau_{\max }$ for a rectangular cross section is given as:

$$
\begin{aligned}
\tau_{\max }=\frac{3 M_{\mathrm{t}}}{8 a b^{2}}[ & 1+0.6095 \frac{b}{a}+0.8865\left(\frac{b}{a}\right)^{2}-1.8023\left(\frac{b}{a}\right)^{3} \\
& \left.+0.9100\left(\frac{b}{a}\right)^{4}\right] .
\end{aligned}
$$

The experimental error $E_{\text {exp }}$ is evaluated by the parametrical error analysis and is determined as:

$$
E_{\exp }[\text { in \% }]=\frac{\Delta J(t)}{J(t)} \times 100=\frac{\sum_{\mathrm{i}=1}^{\mathrm{n}}\left|\frac{\partial J(t)}{\partial x_{\mathrm{i}}} \Delta x_{\mathrm{i}}\right|}{J(t)} \times 100
$$

where $x_{\mathrm{i}}$ denotes each parameter, used in the shear creep compliance $J(t)$ definition.

\section{$\underline{\text { Appendix B (Closed Form Shifting - CFS algorithm) }}$}

The accuracy of the generated master curve and its shift factors depends upon the adopted shifting procedure on the measured segments. The Closed-Form-Shifting (CFS) algorithm is a mathematical formulation for shifting segments along logarithmic time (or frequency) axis [3839]. The algorithm takes into account the segment measured at two different boundary conditions, i.e., at $T_{\mathrm{ref}}$ and $T_{\mathrm{k}}$, which represent the behavior of the material at two thermodynamic states. The shifting of those two segments is possible if the segments have the same energy release rate at all points over the superimposing interval. This criterion may be expressed as

$$
\left.\frac{\mathrm{d} W\left(t, T_{\mathrm{ref}}\right)}{\mathrm{d} \log t}\right|_{t=t_{\mathrm{j}}}=\left.\frac{\mathrm{d} W\left(t, T_{\mathrm{k}}\right)}{\mathrm{d} \log t}\right|_{t=t_{\mathrm{k}}} .
$$


The condition expressed in Eq. (B.1) is fulfilled when the overlapping area $S$ between two segments is equal to zero, as shown in Fig. 13.

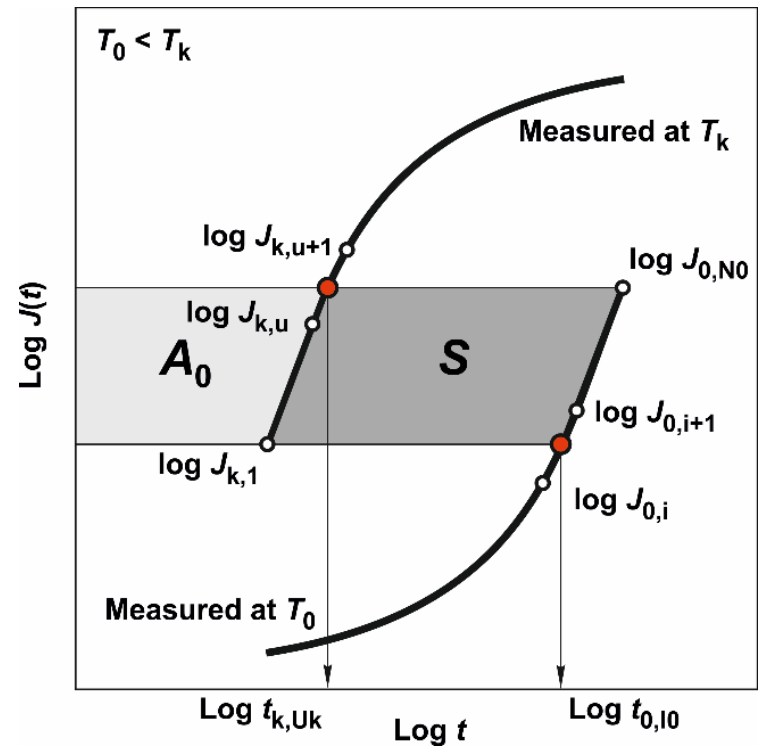

Fig. B1. Schematics of the CFS procedure for an example of shear creep compliance.

This yields the closed form equation for the shift factor:

$$
\log a_{T_{\mathrm{k}}}=\frac{A_{0}-\sum_{\mathrm{u}=\mathrm{I}_{0}}^{\mathrm{N}_{\mathrm{k}}-1}\left[\frac{\log t_{\mathrm{k}, \mathrm{u}+1}+\log t_{\mathrm{k}, \mathrm{u}}}{2} \cdot\left(\log J_{\mathrm{k}, \mathrm{u}+1}-\log J_{\mathrm{k}, \mathrm{u}}\right)\right]}{\log J_{0, \mathrm{~N} 0}-\log J_{0,1}},
$$

where

$$
A_{0}=\sum_{\mathrm{i}=1}^{\mathrm{N}_{0}-1} \frac{\log t_{0, \mathrm{i}}+\log t_{0, \mathrm{i}+1}}{2} \cdot\left(\log J_{0, \mathrm{i}+1}-\log J_{0, \mathrm{i}}\right)
$$

\section{Appendix C (Determination of shear retardation mechanical spectra)}

The shear creep response of a real viscoelastic material can be expressed with a material transfer function, usually determined with the generalized Voight model, or so-called Kelvin model, as

$$
J(t)=J_{\mathrm{e}}-\sum_{\mathrm{i}=1}^{\mathrm{i}=\mathrm{N}} J_{\mathrm{i}} \exp \left(-t / \lambda_{\mathrm{i}}\right)
$$


where, $J_{\mathrm{e}}$ denotes the shear creep compliance in the equilibrium state, and set of $\left\{J_{\mathrm{i}}, \lambda_{\mathrm{i}} ; \mathrm{i}=1,2\right.$, ...,N\} represents discrete shear retardation spectra, defined as $L\left(\lambda_{\mathrm{i}}\right)$, where the compliances are denoted as $J_{\mathrm{i}}$ and the retardations times as $\lambda_{\mathrm{i}}$.

The Windowing algorithm calculates each spectrum line from a subset of the entire set of experimental data [41-42]. This subset is the "window", through which the algorithm scans the data set and determines the spectrum lines. Each window must contain at least one datum point. The width of the window depends on the kernel function $k(t, \lambda)$, which for a viscoelastic material is defined as $k(t, \lambda)=\exp (-t / \lambda)$. Prior to applying the algorithm to experimental data, which is available as a set of $\left\{J\left(t_{\mathrm{j}}\right), t_{\mathrm{j}} ; \mathrm{j}=1,2, \ldots, \mathrm{M}\right\}$, Eq.(C.1) is normalized by using $J_{\mathrm{e}}-J_{\mathrm{g}}$, thus:

$$
j\left(t_{\mathrm{j}}\right)=j_{\mathrm{e}}-\sum_{\mathrm{i}=1}^{\mathrm{i}=\mathrm{N}} j_{\mathrm{i}} \exp \left(-t_{\mathrm{j}} / \lambda_{\mathrm{i}}\right)
$$

where

$j\left(t_{\mathrm{j}}\right)=\frac{J\left(t_{\mathrm{j}}\right)}{J_{\mathrm{e}}-J_{\mathrm{g}}}, j_{\mathrm{e}}=\frac{J_{\mathrm{e}}}{J_{\mathrm{e}}-J_{\mathrm{g}}}$ and $j_{\mathrm{i}}=\frac{J_{\mathrm{i}}}{J_{\mathrm{e}}-J_{\mathrm{g}}}$.

Since $J_{\mathrm{e}}$ and $J_{\mathrm{g}}$ may not be known, one should use $J_{1}-J_{\mathrm{M}}$, the difference between the largest, $J_{1}$, and the smallest, $J_{\mathrm{M}}$, datum point. Each normalized datum point then becomes

$$
\hat{\jmath}\left(t_{\mathrm{j}}\right)=\hat{\jmath}\left(t_{\mathrm{M}}\right)-\sum_{\mathrm{i}=1}^{\mathrm{i}=\mathrm{N}} \hat{\jmath}_{\mathrm{i}} \exp \left(-t_{\mathrm{j}} / \lambda_{\mathrm{i}}\right)+\delta\left(t_{\mathrm{j}}\right)
$$

where

$\hat{\jmath}\left(t_{\mathrm{j}}\right)=\frac{J(t)}{J_{1}-J_{\mathrm{M}}}, \hat{\jmath}\left(t_{\mathrm{M}}\right)=\frac{J\left(t_{\mathrm{M}}\right)}{J_{1}-J_{\mathrm{M}}}$ and $\hat{\jmath}_{\mathrm{i}}=\frac{J_{\mathrm{i}}}{J_{1}-J_{\mathrm{M}}}$.

The last term in Eq. (C.3) accounts for the normalized approximation error, $\delta\left(t_{\mathrm{j}}\right)$, that arises because we replaced, $J_{\mathrm{e}}$ by $\left.\hat{\jmath}_{(\mathrm{M}}\right)$, and because we used $J_{1}-J_{\mathrm{M}}$ instead of $J_{\mathrm{e}}-J_{\mathrm{g}}$. In order to determine the set of spectrum lines, $\left\{\hat{\jmath}_{i}\right\}$, the sum in Eq. (C.3) can be split into three parts, hence

$$
\begin{aligned}
\hat{\jmath}\left(t_{\mathrm{j}}\right)=\hat{\jmath}\left(t_{\mathrm{M}}\right) & -\sum_{\mathrm{i}=1}^{\mathrm{i}=\mathrm{N}} \hat{\jmath}_{\mathrm{i}} \exp \left(-t_{\mathrm{j}} / \lambda_{\mathrm{i}}\right)-\hat{\jmath}_{\mathrm{k}} \exp \left(-t_{\mathrm{j}} / \lambda_{\mathrm{k}}\right) \\
& -\sum_{\mathrm{i}=1}^{\mathrm{i}=\mathrm{N}} \hat{\jmath}_{\mathrm{i}} \exp \left(-t_{\mathrm{j}} / \lambda_{\mathrm{i}}\right)+\delta\left(t_{\mathrm{j}}\right) .
\end{aligned}
$$


Instead of starting the summation with the index 1 , one may use $m=(k-2 n-1) \geq 1$ to reduce the time that the algorithm needs to execute the sweep. Therefore, Eq. (C.4) can be re-written as

$$
\begin{aligned}
\hat{\jmath}\left(t_{\mathrm{j}}\right)=\hat{\jmath}\left(t_{\mathrm{M}}\right) & -\sum_{\mathrm{i}=\mathrm{m}}^{\mathrm{i}=\mathrm{k}-1} \hat{\jmath}_{\mathrm{i}} \exp \left(-t_{\mathrm{j}} / \lambda_{\mathrm{i}}\right)-\hat{\jmath}_{\mathrm{k}} \exp \left(-t_{\mathrm{j}} / \lambda_{\mathrm{k}}\right) \\
& -\sum_{\mathrm{i}=\mathrm{k}+1}^{\mathrm{i}=\mathrm{N}} \hat{\jmath}_{\mathrm{i}} \exp \left(-t_{\mathrm{j}} / \lambda_{\mathrm{i}}\right)+\delta\left(t_{\mathrm{j}}\right) .
\end{aligned}
$$

One should proceed to minimize the approximation error, $\delta\left(t_{\mathrm{j}}\right)$, to obtain an expression for the magnitude of the $\mathrm{k}^{\text {th }}$ spectrum line. The sum of square of $\delta\left(t_{\mathrm{j}}\right)$ within one Window may be defined as

$$
E_{\mathrm{k}}=\sum_{\mathrm{j}=\mathrm{s}_{\mathrm{k}, \mathrm{l}}}^{\mathrm{j}=\mathrm{s}_{\mathrm{k}, \mathrm{u}}} \delta\left(t_{\mathrm{j}}\right)^{2}
$$

where $S_{k, 1}$ and $S_{k, u}$ are, respectively, the first and the last discrete point defining the Window that contains the $\mathrm{k}^{\text {th }}$ spectrum line. The error may now be expressed in the form of Eq. (C.5) as

$$
\begin{gathered}
\delta\left(t_{\mathrm{j}}\right)=\hat{\jmath}\left(t_{\mathrm{j}}\right)-\hat{\jmath}\left(t_{\mathrm{M}}\right)+\sum_{\mathrm{i}=\mathrm{m}}^{\mathrm{i}=\mathrm{k}-1} \hat{\jmath}_{\mathrm{i}} \exp \left(-t_{\mathrm{j}} / \lambda_{\mathrm{i}}\right)+\hat{\jmath}_{\mathrm{k}} \exp \left(-t_{\mathrm{j}} / \lambda_{\mathrm{k}}\right) \\
+\sum_{\mathrm{i}=\mathrm{k}+1}^{\mathrm{i}=\mathrm{N}} \hat{\jmath}_{\mathrm{i}} \exp \left(-t_{\mathrm{j}} / \lambda_{\mathrm{i}}\right) .
\end{gathered}
$$

We minimize $\delta\left(t_{\mathrm{j}}\right)$ according to $\partial E_{\mathrm{k}} / \partial \hat{\jmath}_{\mathrm{k}}=0$, which leads to

$$
\begin{gathered}
\partial E_{\mathrm{k}} / \partial \hat{\jmath}_{\mathrm{k}}=2 \sum_{\mathrm{j}=\mathrm{S}_{\mathrm{k}, \mathrm{l}}}^{\mathrm{j}=\mathrm{s}_{\mathrm{k}, \mathrm{u}}} \frac{\partial \delta\left(t_{\mathrm{j}}\right)}{\partial \hat{\jmath}_{\mathrm{k}}}=0, \text { and } \\
\hat{\jmath}_{\mathrm{k}}=\frac{\sum_{\mathrm{j}=\mathrm{S}_{\mathrm{k}, \mathrm{l}}}^{\mathrm{j}=\mathrm{s}_{\mathrm{u}}} \Phi_{\mathrm{m}} \exp \left(-t_{\mathrm{j}} / \lambda_{\mathrm{k}}\right)}{\sum_{\mathrm{j}=\mathrm{S}_{\mathrm{k}, \mathrm{l}}}^{\mathrm{j}=\mathrm{S}_{\mathrm{k}}} \exp \left[-2\left(-t_{\mathrm{j}} / \lambda_{\mathrm{k}}\right)\right]}
\end{gathered}
$$

where $\Phi_{\mathrm{m}}$ is defined as 


$$
\Phi_{\mathrm{m}}\left(t_{\mathrm{j}}\right)=\hat{\jmath}\left(t_{\mathrm{j}}\right)-\hat{\jmath}\left(t_{\mathrm{M}}\right)+\sum_{\mathrm{i}=\mathrm{m}}^{\mathrm{i}=\mathrm{k}-1} \hat{\jmath}_{\mathrm{i}} \exp \left(-t_{\mathrm{j}} / \lambda_{\mathrm{i}}\right)+\sum_{\mathrm{i}=\mathrm{k}+1}^{\mathrm{i}=\mathrm{N}} \hat{\jmath}_{\mathrm{i}} \exp \left(-t_{\mathrm{j}} / \lambda_{\mathrm{i}}\right)
$$

\section{Appendix D (Williams Landel Ferry - WLF equation)}

The thermal shift function determines the time-temperature relationship of a given material, which can be modeled with the well-established free volume concept based on the Williams Landel Ferry - WLF equation given as [35, 43]

$$
\log a_{T}(T)=-\frac{c_{1}\left(T-T_{\mathrm{ref}}\right)}{c_{2}+T-T_{\mathrm{ref}}}
$$

where, $T$ is the selected temperature of shift, $T_{\text {ref }}$ is the reference temperature, and $c_{1}, c_{2}$ are so called material constants.

\section{References}

[1] Astrom BT. Manufacturing of Polymer Composites, 1st Edition. CRC Press, 1997.

[2] Muhmid B, Imad A, Benseddiq N, Benmedakhene S, Maazouz A. A Study of the Mechanical Behaviour of Glass Fiber Reinforced Polyamide 6,6: Experimental investigation. Polymer testing 2006;25(4):544-552.

[3] Schoßig M, Bierögel C., Grellman W, Mecklenburg T. Mechanical Behavior of GlassFiber Reinforced Thermoplastic Materials Under High Strain Rates. Polymer testing 2008;27(7):893-900.

[4] Fu SY, Lauke B, Mäder E, Yue CY, Hu X. Tensile Properties of Short-Glass-Fiberand Short-Carbon-Fiber-Reinforced Polypropylene Composites. Composites: Part A 2000;31(9):1117-1125.

[5] Kuruvilla J, Sabu T, Pavitrah C. Viscoelastic Properties of Short-Sisal-Fiber-Filled Low-Density Polyethylene Composites: Effect of Fiber Length and Orientation. Materials Letters 1992;15(4):224-228.

[6] He M, Zhang F, Guo J, Qin S, Ming X. Mechanical, Thermal, and Dynamic Mechanical Properties of Long Glass Fiber-Reinforced Thermoplastic 
Polyurethane/Polyoxymethylene Composites. Polymer Composites 2014;35(10):2067-2073.

[7] Saeed U, Hussain K, Rizvi H. HDPE Reinforced With Glass Fibers: Rheology, Tensile Properties, Stress Relaxation and Orientation of Fibers. Polymer Composites 2014;35(11):2159-2169.

[8] Bartilsson H, Franzén B, Klason C, Kubát A, Kitano T. The influence of Procession on Fiber Orientation and Creep in Short Carbon-Fiber Reinforced Low Density Polyethylene and Polycarbonate. Polymer Composites 1992;13(2):121-132.

[9] Obaid N, Kortschot MT, Sain M. Modeling and Prediction the Stress Relaxation of Composites with Short and Randomly Oriented Fibers. Material 2017;10(10):1207.

[10] Obaid N, Kortschot MT, Sain M. Understanding the Stress Relaxation Behavior of Polymers Reinforced with Short Elastic Fibers, Materials, 10(5);2017:472.

[11] Obaid N, Kortschot MT, Sain M. Predicting the Stress Relaxation Behavior of GlassFiber Reinforced Polypropylene Composites. Composite Science and Technology 2018;161:85-91.

[12] Pan N. Theoretical Determination of Optimal Fiber Volume Fraction and Fiber-Matrix Property Compatibility of Short Fiber Composites. Polymer Composites 1993;14(2):85-93.

[13] Bowman S, Jiang Q, Memon H, Qiu Y, Liu W, Wei Y. Effects of Styrene-Acrylic Sizing on Mechanical Properties of Carbon Fiber Thermoplastic Towpregs and Their Composites. Molecules 2018;23(3):547.

[14] Thomason JL, Adzima LJ. Sizing Up the Interphase: An Insider's Guide to the Science of Sizing. Composites: Part A 2001;32(3-4):313-321.

[15] Blackketter DM, Upadhyaya D, King TR, King JA. Evaluation of Fiber Surface Treatment and Sizing on the Shear and Transverse Tensile Strength of Carbon FiberReinforced Thermoset and Thermoplastic Matrix Composites. Polymer Composites 1993;14(5):430-436.

[16] Kallel TK, Guermazi N, Taktak R, Mnif N. Mechanical and Structural Properties of Glass Fiber-Reinforced Polypropylene (PPGF) Composites. Polymer Composites 2018;39(10):3497-3508 
[17] Sreenivasan VS, Rajini N, Alavudeen A, Arumugaprabu V. Dynamic mechanical and thermo-gravimetric analysis of Sansevieria Cylindrica/polyester composites: Effect of Fiber Length, Fiber Loading, and Chemical Treatment. Composites: Part B 2015;69:76-86.

[18] Zhang D, He M, Qin S, Yu J. Effect of Fiber Length and Dispersion on Properties of Long Glass Fiber Reinforced Thermoplastic Composites Based on Poly (Butylene Terephathalate). RSC Advances 2017;7(25):15439-15454.

[19] Houshyar S, Shanks RA. Tensile Properties and Creep Response of Polypropylene Fibre Composites with Variation of Fibre diameter. Polymer international 2004;53(11):1752-1759.

[20] Thomason JL. The Influence of Fiber Properties of the Performance of Glass-FibreReinforced Polyamide 6,6. Composite Science and Technology 1999;59 (16):23152328.

[21] Ramstainer F, Theysohn R. The Influence of Fiber Diameter on the Tensile Behavior of Short-Glass-Fibre Reinforced Polymers. Composites Science and Technology 1985;24(3):231-240.

[22] McNally D, Short Fiber Orientation and its Effect on the Properties of Thermoplastic Composit Material. Polymer-Plastics Technology and Engineering 1977:8(2):101154.

[23] Akay M, Barkley D. Fiber Orientation and Mechanical Behavior in Reinforced Thermoplastic Injection Mouldings. Journal of Material Science 1991;26(10):27312742.

[24] Nicri M, Notta-Cuvier D, Lauro F, Chaari F, Zouari B, Maalej Y. A ViscoelasticViscoplastic Model for Short-Fibre Reinforced Polymers with Complex Fibre Orientations. EPJ Web of Conferences 2015;94.

[25] Notta-Cuvier D, Nicri M, Lauro F, Dalille R, Chaari F, Robache F, Haugou G, Maalej Y. Coupled Influence of Strain Rate and Heterogeneous Fibre Orientation on the Mechanical Behaviour of Short-Glass-Fibre Reinforced Polypropylene. Mechanics of Materials 2016;100:186-197 
[26] Pipes RB, Mccullough RL, Taggart DG. Behavior of Discontinuous Fiber Composites: Fiber Orientation. Polymer Composites 1982;3(1):34-39.

[27] Papanicolaou GC, Zaoutsos SP, Kontou EA. Fiber Orientation Dependence of Continuous Carbo/Epoxy Composites Nonlinear Viscoelastic Behavior. Composites Science and Technology 2004;64(16):2535-2545

[28] Celanese, Ticona, Material data sheet: Fortron MT 9141 L4.

[29] A. Oseli A, A. Aulova A, M. Gergesova M, I. Emri I. Effect of temperature of mechanical properties of polymers. In: Altenbach H, Öchsner A. Encyclopedia of Continuum Mechanics. Springer 2021.

[30] Kovacs AJ. Transition vitreuse dans les polymers amorphes: Etude phénoménologique. Fortschr. Hochnpolymeren-Forschung 1967;3:394-507.

[31] Struik LCE. Physical aging in plastics and other glassy materials. Polymer engineering and science 1977;17:165-173.

[32] ISO 6721-11:2012; Plastics - Determination of dynamic mechanical properties - Part 11: Glass transition temperature.

[33] K.P. Menard KP. Dynamic Mechanical Analisys: A Practical Introduction. CRC Press, 2008.

[34] Plazek DJ, Ngai KL. Glass Transition Temperature. In: Mark JE. Physical Properties of Polymers Handbook, Springer, 2007.

[35] Tschoegl NW, Knauss WG, Emri I. The Effect of Temperature and Pressure on Mechanical Properties of Thermo- and/or Piezorheological Simple Polymeric Materials in Thermodynamic Equillibrium - A critical review. Mechanics of TimeDependent Materials 2002;6(1):53-99.

[36] McKenna GB. Mechanical rejuvenation in polymer glasses: fact or fallacy?. Journal of Physics: Condensed Matter 2003;15():737-763.

[37] Young WC, Budynas RG. Roark's Formulas for Stress and Strain, McGraw-Hill, 2002.

[38] Gergesova M, Zupančič B, Saprunov I, Emri I. The closed form t-T-P shifting (CFS) algorithm, Journal of rheology 2010;55 (1):1-16. 
[39] ISO 18437-6:2017; Mechanical vibration and shock -- Characterization of the dynamic mechanical properties of viscoelastic materials - Part 6: Time-temperature superposition.

[40] Tschoegl NW. The phenomenological theory of linear viscoelastic behavior: An Introduction. Springer, 2007.

[41] I. Emri I, M. Gergesova M. Time-dependent behavior of solid polymers. In: Encyclopedia of Life support systems. Unesco, 2010.

[42] Emri I, Tschoegl NW. Generating line spectra from experimental response. Part I: Relaxation modulus and creep compliance. Rheological acta 1993;32(3):311-321.

[43] Ferry JD. Viscoelastic properties of polymers. John Wiley \& Sons, 1980. 